\title{
Shore-Based Video Observations of Nonlinear Internal Waves across the Inner Shelf ${ }^{*}+$
}

\author{
Sutara H. Suanda, John A. Barth, Rob A. Holman, And John Stanley \\ College of Earth, Ocean and Atmospheric Sciences, Oregon State University, Corvallis, Oregon
}

(Manuscript received 2 May 2013, in final form 13 December 2013)

\begin{abstract}
Shore-based video remote sensing is used to observe and continually monitor nonlinear internal waves propagating across the inner shelf. Month-long measurements of velocity from bottom-mounted acoustic Doppler current profilers and temperature from thermistor chains at the 10- and 20-m isobaths are combined with sea surface imagery from a suite of cameras (Argus) to provide a kinematic description of 11 borelike internal waves as they propagate across the central Oregon inner shelf. The surface expression of these waves, commonly seen by eye as alternating rough and smooth bands, are identified by increased pixel intensity in Argus imagery (average width $39 \pm 6 \mathrm{~m}$ ), caused by the convergence of internal wave-driven surface currents. These features are tracked through time and space using 2-min time exposure images and then compared to wave propagation speed and direction from in situ measurements. Internal waves are refracted by bathymetry, and the measured wave speed $\left(\sim 0.15 \mathrm{~m} \mathrm{~s}^{-1}\right)$ is higher than predicted by linear theory $\left(<0.1 \mathrm{~m} \mathrm{~s}^{-1}\right)$. Propagating internal waves are also visible in subsampled Argus pixel time series (hourly collections of $17 \mathrm{~min}$ worth of $2-\mathrm{Hz}$ pixel intensity from a subset of locations), thus extending the observational record to times without an in situ presence. Results from this 5-month record show that the preferred sea state for successful video observations occurs for wind speeds of $2-5 \mathrm{~m} \mathrm{~s}^{-1}$. Continued video measurements and analysis of extensive existing Argus data will allow a statistical estimate of internal wave occurrence at a variety of innershelf locations.
\end{abstract}

\section{Introduction}

The inner shelf occupies water depths between 10 and $50 \mathrm{~m}$, and is the transition between the typically unstratified surf zone and the deeper, stratified regions characteristic of the continental shelf. Intermittent, nonlinear, high-frequency internal waves and bores are frequently observed at these depths at many different coastal locations (e.g., Pineda 1999; Leichter et al. 1996; Scotti and Pineda 2004; Walter et al. 2012). The high level of interest in these features and their impact on the circulation in this region is due to the potential contribution of these waves to the mixing and transport

\footnotetext{
* Supplemental information related to this paper is available at the Journals Online website: http://dx.doi.org/10.1175/JTECH-D13-00098.s1.

${ }^{+}$Partnership for Interdisciplinary Studies of Coastal Oceans Contribution Number 432.

Corresponding author address: Sutara H. Suanda, College of Earth, Ocean and Atmospheric Sciences, 104 CEOAS Administration Building, Corvallis, OR 97331-5503.

E-mail: asuanda@coas.oregonstate.edu
}

of pollutants and nutrients (e.g., Wong et al. 2012), plankton (e.g., Leichter et al. 1996), and invertebrate larvae (e.g., Pineda 1999). As internal waves propagate into shallow-water, observational, laboratory, and modeling studies all show that nonlinear effects become important as the waves steepen and potentially disperse during the shoaling and breaking process (e.g., Helfrich 1992; Venayagamoorthy and Fringer 2007). Thus, in this paper, the definition of an internal wave is quite broad and encompasses many forms of stratified shallow-water internal activity, including nonlinear soliton-type features as well as internal borelike features. The combination of these forms is sometimes referred to in the literature as solibores (Henyey and Hoering 1997).

On the Oregon shelf, moored, shipboard, and drifter observations of internal waves have concentrated on deeper parts of the continental shelf, providing excellent detail on their physical properties, such as frequency distribution and energy transformation (Stanton and Ostrovsky 1998; D'Asaro et al. 2007; Moum et al. 2007). Over the shallow inner shelf, however, not as much information is available. Furthermore, the arrival timing of internal waves to continental shelves with open coastlines is hard to predict due to time-varying background 
conditions and multiple potential sources of internal wave generation (Nash et al. 2012), and thus long-term monitoring is needed.

Though the inner shelf is relatively close to shore and potentially accessible to smaller research vessels, it is difficult to maintain long-term in situ instrumentation in shallow water. The shoaling and breaking of incoming surface gravity waves may cause damage and loss to equipment by physically transporting or burying them under sand and sediment. The heave of surface waves can also break moored surface lines, leaving bottommounted instruments stranded on the ocean floor. A cost-effective alternative to in situ measurement, especially for physical processes with a clear surface expression, is remote sensing.

Remote sensing of internal waves has been explored by both satellite and X-band radar. The convergent and divergent surface currents associated with internal waves modulate the intensity of Bragg scattering on the ocean's surface, which is visible to radar as alternating bright and dark bands (e.g., Apel et al. 1985; Kropfli et al. 1999). Satellite observations from synthetic aperture radar (SAR) have sampled coastlines around the globe, and maps of internal wave signatures from many regions have been made available (Jackson 2004). However, the infrequent passes of an Earth-orbiting satellite have prohibited the use of SAR as a consistent monitoring method. X-band radar observations have been most useful as a shipboard instrument to complement mooring measurements (Kropfli et al. 1999; Ramos et al. 2009; Shroyer et al. 2011). Unfortunately, most large oceanclass research vessels cannot sail into shallow shelf waters and nonlinear transformations cause internal wave surface signatures to become difficult to distinguish in $\mathrm{X}$-band radar imagery. Our attempts to observe innershelf internal waves by shore-based X-band radar during summer of 2010 were unsuccessful.

Optical measurements through video or still photo observations of the sea surface offer another remote sensing possibility. The convergent surface flows are visible to cameras as regions of elevated pixel intensity (e.g., Chang et al. 2008). With a smaller measurement footprint than satellite, and based on land or taken from aircraft (Wang and Pawlowicz 2011), the use of commercial digital cameras is a potential low-cost observational method. Pawlowicz (2003) showed the utility of shore-based photography to record properties of shallowwater internal waves and other shelf-estuarine flows with clear surface signatures. Previous internal wave studies using cameras have been conducted for limited duration and with targeted wave behavior. Bourgault et al. (2011) observed tidally generated internal waves propagating into an enclosed fjord system within the Gulf of Saint
Lawrence where the timing of wave arrival was predictable. While there have been relatively few studies of inner-shelf internal waves on open coastlines with optical remote sensing, video cameras have been used frequently and consistently to study surf zone processes, such as the propagation of surface waves and sediment transport (Holman and Stanley 2007).

The first purpose of this paper is to show that the surface signature of shallow-water high-frequency internal waves can be observed on an open coastline by shore-based optical remote sensing. Sea surface video imagery can provide useful estimates of wave properties, such as the two-dimensional surface structure, phase speed, incoming direction, and width of associated surface convergence. The second goal is to demonstrate the consistent monitoring of these onshore-propagating features with video remote sensing. As video remote sensing produces large volumes of data, we use subsampled pixel time series that can still identify the surface signature of internal waves within a range of overlying wind speed magnitudes. The methods used, including data processing and wave identification, are described in section 2, with a specific example of a tracked internal wave. Results from a combined in situ and remote sensing experiment, as well as the use of remotely sensed data alone, are presented in section 3. Further developments of the technique and potential benefits from the approach are summarized in section 4. Finally, conclusions are presented in section 5 .

\section{Methods}

\section{a. In situ measurements and data processing}

To illustrate the technique and capability of a permanent video installation to capture the surface expression of shoreward-propagating internal waves on the open coast, a combined in situ and remote sensing observational experiment was conducted during the month of August 2011 off Yaquina Head near Newport, Oregon (Fig. 1).

Two moorings were deployed on the 10- and 20-m isobaths, $2 \mathrm{~km}$ south of Yaquina Head. Both moorings had an L-shaped configuration with bottom-mounted acoustic Doppler current profiler (ADCP) measurements of velocity [Teledyne RD Instruments (RDI) Workhorse], connected to a string of thermistors to capture thermal stratification (RBR TR-1060) and top-bottom (20-m location only) salinity measurements [Sea-Bird Electronics (SBE)-37 and SBE-16plus] (Table 1). The $10-\mathrm{m}(20 \mathrm{~m})$ ADCPs were set to sample in currentprofile mode, creating ensembles of 10 profiles every $10 \mathrm{~s}$ in $0.5-\mathrm{m}(1 \mathrm{~m})$ bins. In postdeployment processing, all 
(a)

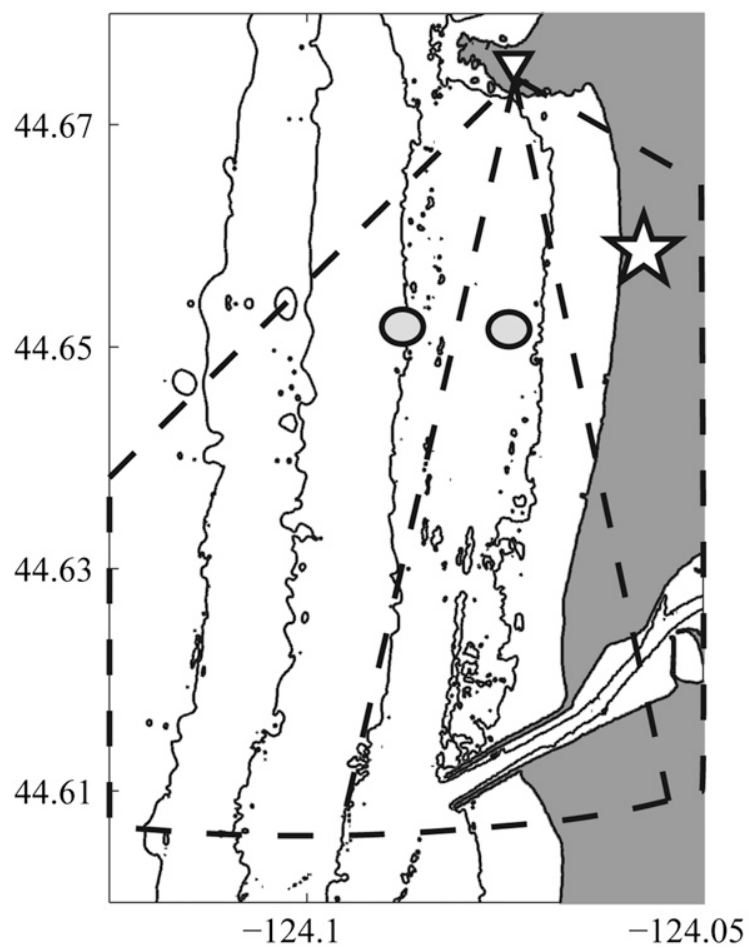

(b)

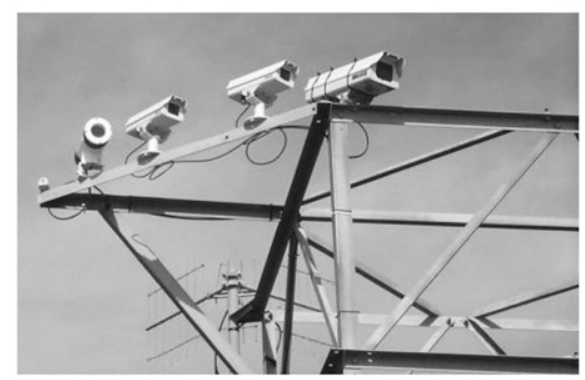

(c)

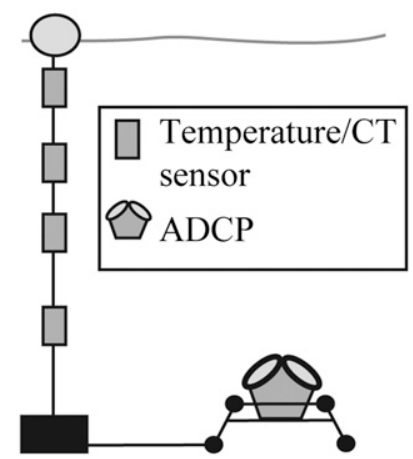

FIG. 1. (a) Bathymetry around Newport along with locations of in situ moorings (gray circles) and approximate field of views for three Argus cameras. Thin gray lines denote the 10-, 20-, 30-, and 40-m isobaths. Star marks the origin of Argus coordinate system (0,0). (b) Argus camera tower at Yaquina Head (photo courtesy of R. Holman). (c) Diagram of mooring configuration. Details of instrument depths are given in Table 1.

temperature, salinity, and velocity data are averaged into 30-s intervals.

High-frequency, nonlinear, first-mode internal waves are a strong source of midwater-column vertical velocity and temperature fluctuations in a stratified fluid. An example of an internal borelike wave of depression from 15 August 2011 is shown in Fig. 2. Unlike solitary wave measurements from deeper parts of the ocean with clearly defined leading and trailing edges, the sharp downward isotherm displacement, which approximately coincides with an elevated surface convergence and large downwelling velocities, does not have a corresponding upward displacement (there is no trailing edge).

To identify these waves in the mooring record, a detection algorithm was developed to analyze both time series of midwater-column vertical velocity and temperature. In 24-h increments, a first-difference filter is applied to the temperature records from the 7-, 10-, and $13-\mathrm{m}(4,7 \mathrm{~m})$ thermistors at the $20-\mathrm{m}(10 \mathrm{~m})$ site, and the largest values ( $>3$ standard deviations) are identified as potential internal wave events. Vertical velocity time series from three midwater-column ADCP bins (25\%, $50 \%$, and $75 \%$ of water depth) are also analyzed to identify their largest fluctuations ( $>3$ standard deviations). When large oscillations coincide in temperature and velocity, the 30 -s period is identified as the leading edge of an internal wave. By comparing the average midwatercolumn temperature in the 10-min interval prior to wave arrival with the 10-min interval following the leading edge, the algorithm also distinguishes the polarity of an

TABLE 1. Instrumentation during combined experiment.

\begin{tabular}{ccccc}
\hline \hline $\begin{array}{c}\text { Mooring } \\
(\mathrm{m})\end{array}$ & $\begin{array}{c}\text { Deployment } \\
\text { duration }\end{array}$ & $\begin{array}{c}\text { ADCP frequency } \\
(\mathrm{kHz})(\text { 10-s sample interval) }\end{array}$ & $\begin{array}{c}\text { Temperature measurement } \\
\text { depths (5-s sample interval) }\end{array}$ & $\begin{array}{c}\text { Salinity measurement } \\
\text { depths (10-s sample interval) }\end{array}$ \\
\hline 10 & 3 Aug-12 Sep 2011 & 1200 & $1,4,7,10$ & 1 \\
20 & 31 Jul-1 Sep 2011 & 600 & $1,4,7,10,13,17,20$ & 1,20 \\
\hline
\end{tabular}


(a)

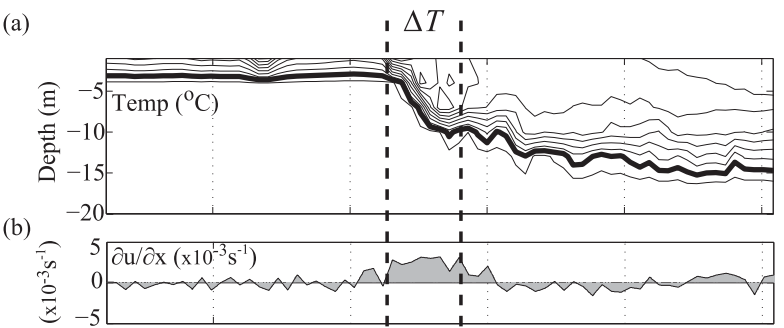

(c)

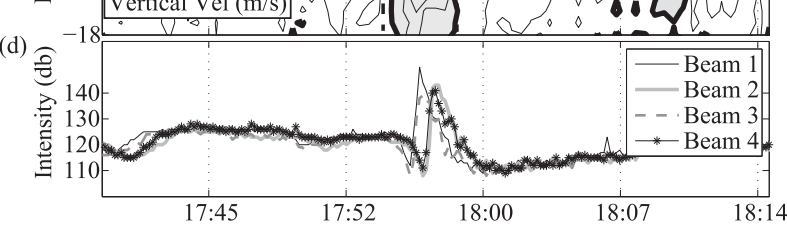

FIG. 2. Internal wave measured at 20-m mooring on 15 Aug 2011 (time is UTC). (a) Contoured temperature from thermistor chain. Thick contour is $8.5^{\circ} \mathrm{C}$, and contour interval is $0.3^{\circ} \mathrm{C}$. (b) Surface convergence as measured from the topmost good ADCP bin measurement. (c) Contoured vertical velocity from ADCP. Thick contour is $0 \mathrm{~m} \mathrm{~s}^{-1}$, and contour interval is $0.01 \mathrm{~m} \mathrm{~s}^{-1}$. Negative velocity values (downwelling) are shaded. (d) Beam intensity time series from four beams at ADCP bin located $6 \mathrm{~m}$ below sea surface.

internal wave. With the passing of the leading edge, depression events show a warming of the midwater column, while elevation events show water-column cooling. Details of the variety and timing of these inner-shelf internal wave events will be discussed in a future paper.

The amount of surface-layer convergence can be estimated a number of ways from the moorings. From the ADCPs, the rate of change of the surface-most horizontal velocity measurement in the direction of wave propagation gives a direct estimate of horizontal convergence even if it is located a few meters below the surface. From the continuity equation, the horizontal convergence is accompanied by a downwelling vertical velocity associated with the wave (values that exceed $0.005 \mathrm{~m} \mathrm{~s}^{-1}$ ). Last, the downward isotherm displacement from the moored vertical temperature array also corresponds to this convergence. For a wave of depression (elevation), this convergence is found in front of the wave, at the leading (trailing) edge of the wave. An example of the three mooring-derived convergence estimates is shown in Fig. 2. The measure of duration $(\Delta T)$ is then transformed into a measure of length $(\Delta L)$ in meters by the assumption of frozen flow using the propagation speed estimated above:

$$
\Delta L=\Delta T \times V .
$$

Wave direction and phase speed from the in situ moorings are determined by treating the four beams of each ADCP as a four-element wave-detection array following previous methods (Scotti et al. 2005; Mirshak and Kelley 2009). As internal waves depress or elevate scattering layers within the water column, variations in echo intensity are measured by each ADCP transducer (see Fig. 2d for an example). The timing of the drop or increase in intensity at the four separate ADCP beams gives four independent measurements of the wave event as it passes over the ADCP. RDI Workhorse instruments are set up with two perpendicular pairs of opposite-facing beams (the Janus configuration) at $20^{\circ}$ inclination. With this angle and the measured vertical distances between the unit and beam centers (bin depths), the angles $\left(\varphi_{i j}\right)$ and horizontal distances between each beam $\left(\Delta x_{i j}\right)$ are known. Similar to published methods, the maximum in time-lagged cross correlation between each beam is calculated $\left(\tau_{i j}\right)$, and estimates of the propagation speed $(V)$ and angle of propagation $(\theta)$ are used so as to minimize the value of the squared error $(E)$ in the function

$$
E=\sum_{k=1}^{5} \sum_{i>j}\left[\tau_{i j} V-\Delta x_{i j} \cos \left(\theta-\varphi_{i j}\right)\right]_{k}^{2} .
$$

The inner summation represents the six possible beam lag pairs at a given depth. The second summation $(k)$ is over five independent bin depths. As speed and direction are calculated for both waves of depression and elevation and the depth of the greatest vertical gradient in echo intensity is not known a priori, information from multiple depths are used simultaneously in the minimization. Lower in the water column, the distance between beam centers is small, providing less accurate measurements of the travel speed across transducers. The estimates of speed and direction in this work include measurements from ADCP bins centered between 8 and $13 \mathrm{~m}$ above the bottom.

\section{b. Optical remote sensing collection and processing}

One of the programs to advance the use of optical remote sensing of coastal processes is the Argus program developed at Oregon State University (OSU). An Argus system consists of a suite of cameras rigidly mounted to a tower with synchronized image sampling via a computer-controlled data acquisition and transmission system. The Argus program currently comprises about 10 such installations around the world (Holman and Stanley 2007). Some of the Argus program's capabilities and sampling strategies are discussed below in the context of internal wave observing; however, the reader is referred to that text for a detailed review of these topics and a comprehensive list of references. 
(a)

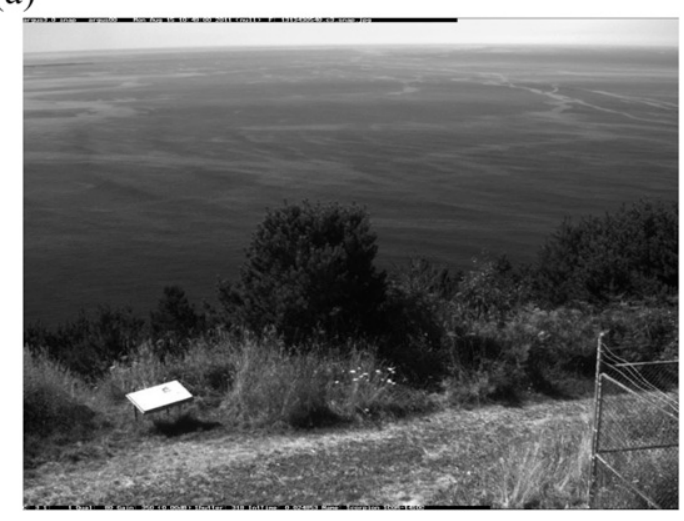

(b)

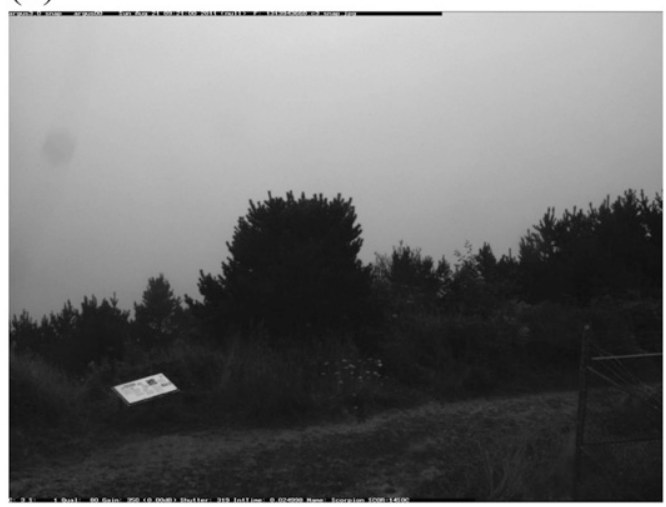

FIG. 3. (a) Example snapshot image from one Argus camera at 1049 Pacific daylight time (PDT), 15 Aug 2011. The tracked onshore-propagating streak can be seen in the top right. This image had the highest possible value on the image clarity index (1). (b) An image with low contrast (0.74).

Video remote sensing for this study is from three cameras mounted $125 \mathrm{~m}$ above sea level, which provide an approximately $70^{\circ}$ field of view to the south of Yaquina Head. The oblique camera images (Fig. 3) are merged into a $2 \mathrm{D}$ plan view in Earth coordinates that spans $\sim 5 \mathrm{~km}$ in the alongshore and up to $3 \mathrm{~km}$ offshore (Holman and Stanley 2007). The Argus right-hand coordinate system is defined such that $x$ is the cross-shelf coordinate and $y$ is the along-shelf coordinate with the origin $(0,0)$ defined as the location of a topographic beach feature (Fig. 4).

Optical remote sensing with digital cameras has the capability to collect and record images at the frequency of the shutter speed $(30 \mathrm{~Hz}$ for Argus cameras). The Argus program has resulted in a variety of sampling schemes adapted to the study of different nearshore processes, including longshore currents, beach profiles, rip currents, and sandbar migration (Holman and Stanley 2007). In this work we use two products: single images consisting of 2-min time exposures (timex) during the combined experiment to track the cross-shelf propagation of internal waves and pixel time series for the 5-month monitoring study to determine internal wave occurrence.

In the near shore, the optical expression of internal waves is not as strong as other signals (i.e., breaking surface waves). To take advantage of the slower propagation speed of internal oscillations and to average out optical noise due to surface waves, 2-min time exposure images are used instead of instantaneous snapshots. Time exposures were taken every 2 min during daylight hours for the duration of the combined experiment. This sampling strategy produced a large amount of image data $(\sim 10 \mathrm{~GB})$ that were stored at an on-site computer and then downloaded after recovery of the in situ moorings.
The second goal of this work was to assess the utility of the Argus installation to continuously monitor the sea surface for the signature of internal waves in the absence of in situ measurements. The standard Argus protocol is

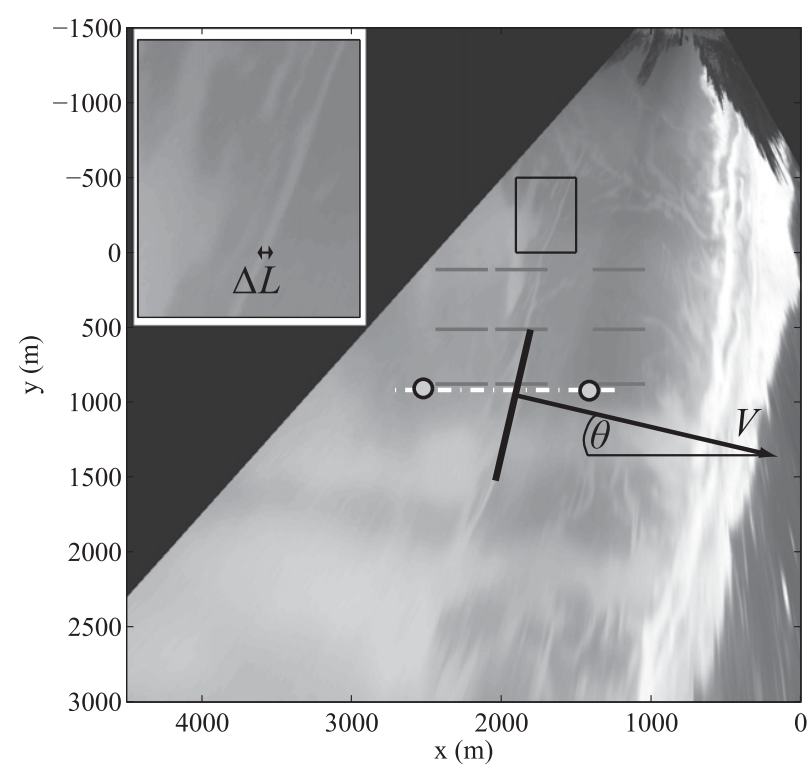

FIG. 4. Georectified and merged time exposure image from Argus with the tracked internal wave from 15 Aug 2011. The coastline is to the right and is made visible by the strong return of surface gravity wave breaking in the near shore. Locations of both moorings are marked by gray circles. Dashed-dotted white line is the cross-shelf transect used for the Hovmöller plot in Fig. 5a. Gray lines show the nine transects where 2D Fourier transforms are computed in the pixel time series. Black line between the moorings shows the fit through the bright streak seen in the image. Inset gives an enlarged view of the outlined box. Estimated wave properties of propagation speed, angle to shore, and convergence width $(V, \theta$, and $\Delta L$ ) are also noted. 
to transfer images from the on-site computer to a local machine at OSU via modem. However, transferring continuous 2-min images is not feasible over extended periods of time due to the bandwidth limitations at the remote sampling station. Thus, for the monitoring assessment, as well as for potential future real-time application, a pixel time series product is used instead. A pixel time series is a once-per-hour Argus sampling routine that records $2 \mathrm{~Hz}$ of image intensity for $17 \mathrm{~min}$ from a subset of pixels within the camera field of view (approximately one pixel every $40 \mathrm{~m}$ in the along-shelf direction and $10 \mathrm{~m}$ in the across-shelf direction). The handling of image and pixel time series collections, data storage, image merges, and georectification are all done using UNIX and matrix laboratory (MATLAB) tools previously developed by members of the Argus team (Holman and Stanley 2007).

The following procedure was used to determine wave properties from Argus timex images during the August 2011 experiment (Fig. 4). Sequences of georectified 2-min timex images were inspected for possible surface features, such as dark-bright bands, streaks, or slicks that surrounded the time of internal wave arrival at in situ moorings from the detection method described in section $2 \mathrm{a}$. Once a coincident occurrence was identified, the timex image corresponding to when the surface feature first enters the Argus field of view is run through a 2D spatial high-pass filter to accentuate the streak representing the wave front. A $1.5-\mathrm{km}$ best-fit line is found through the high-passed points near the wave front centered on the mooring line $(y=915 \mathrm{~m})$. While the propagation direction of a highly curved front, such as a river plume, might not be perpendicular to its orientation everywhere, in our study fronts were mostly oriented in the along-shelf direction and propagation direction is assumed to be perpendicular to front orientation. The procedure was repeated every three image frames for as long as successive images contained the streak. The change in position of the front through time provides an estimate of the propagation speed of the feature as it travels across the inner shelf. Within each frame, the thickness of the front is also estimated by retrieving image intensity values $250 \mathrm{~m}$ in front of and behind the tracked feature to identify the area of increased pixel intensity (Fig. 5b). These results are presented in the following section and summarized in Table 2 for all waves tracked in this study.

As an example, the multiplatform observations of the 15 August internal wave are presented in Fig. 5 as well as in the online supplemental material (see file JTECH-D13-00098s1). A cross-shelf transect of image intensity through time is shown as a Hovmöller plot (Fig. 5a). A region of increased pixel intensity enters the camera (a)

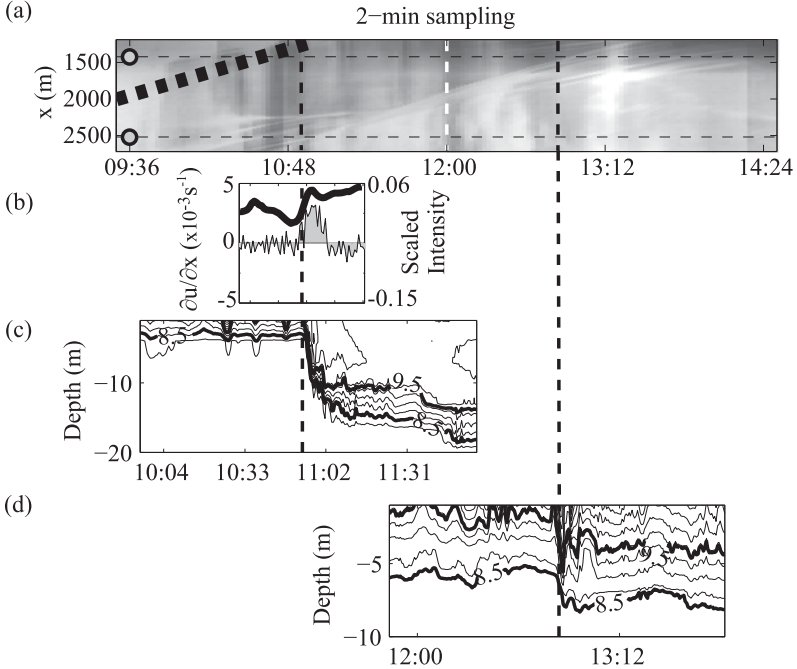

FIG. 5. Internal wave tracked from 15 Aug 2011 (time is PDT). Note that an animated version is posted as supplemental material (file JTECH-D-13-00098s1). (a) Cross-shelf distance vs time (Hovmöller) plot of image intensity from the mooring line. The surface signature of the onshore-propagating internal front is seen to transit through this image. Mooring locations are denoted by gray circles and horizontal dotted lines. Thick black vertical line gives the orientation of a feature propagating at $0.15 \mathrm{~m} \mathrm{~s}^{-1}$. Vertical white line marks the start of the 17-min pixel time series collection (1159 PDT) shown in Fig. 6. (b) Velocity convergence (repeated from Fig. 2) along with an averaged cross-streak intensity from the Argus image at the time of internal wave crossing of the $20-\mathrm{m}$ mooring as described in the text. Gray shaded areas indicate the difference between positive and negative values. (c) Temperature section from 20-m mooring. (d) Temperature section from 10-m mooring.

field of view (1045 PDT, $x=2600)$ and propagates onshore, coincident with large isotherm displacements as the front crosses the moorings. These images taken over $5 \mathrm{~h}$ provide a clear example of a shoreward-propagating streak; however, the same feature is also seen in a Hovmöller plot created from a 17-min pixel time series collection taken at 1200 PDT on that day (Fig. 6a). An internal wave travels $\sim 150 \mathrm{~m}$ during this time, a small portion of the inner-shelf width $(2 \mathrm{~km})$ and not useful for wave-tracking purposes, but a distance easily greater than the measurement error of the cameras and potentially useful for wave detection.

To explore wave detection, two internal wave-finding algorithms were applied to 5 months of the pixel time series data record (June-October 2011). The first algorithm performs an analysis in the frequency-wavenumber domain utilizing fast Fourier transforms (FFT). A similar method has been applied to Argus images to measure surf zone long-shore currents (Chickadel et al. 2003). In this method, pixel time series from each 17-min sampling period are sampled along nine 350-m crossshore transects within the Argus field of view (Fig. 4). 
TABLE 2. Summary of internal waves observed during combined experiment.

\begin{tabular}{|c|c|c|c|c|c|c|}
\hline $\begin{array}{l}\text { Wave No. } \\
\text { (date Aug) }\end{array}$ & $\begin{array}{c}\text { Wave type } \\
\text { (depression or } \\
\text { elevation) }\end{array}$ & $\begin{array}{c}\text { Duration of } \\
\text { video observations } \\
\text { (hours:min) }\end{array}$ & $\begin{array}{l}\text { No. of line fits } \\
\text { during video } \\
\text { observations }\end{array}$ & $\begin{array}{l}\text { Cross-shelf distance } \\
\text { wave tracked }(\mathrm{m})\end{array}$ & $\begin{array}{l}\text { Average wave } \\
\text { speed }\left(\mathrm{m} \mathrm{s}^{-1}\right)\end{array}$ & $\begin{array}{c}\text { Thickness of } \\
\text { streak (m) }\end{array}$ \\
\hline $1(5)$ & D & 4:06 & 42 & 975 & 0.07 & $38 \pm 7$ \\
\hline $2(9)$ & D & $2: 24$ & 25 & 1142 & 0.13 & $39 \pm 4$ \\
\hline $3(10)$ & $\mathrm{D}$ & $2: 18$ & 24 & 549 & 0.07 & $39 \pm 4$ \\
\hline $4(10)$ & $\mathrm{E}$ & $1: 24$ & 15 & 342 & 0.07 & $30 \pm 7$ \\
\hline $5(11)$ & $\mathrm{D}$ & $1: 18$ & 14 & 887 & 0.19 & $35 \pm 8$ \\
\hline $6(14)$ & $\mathrm{D}$ & $1: 48$ & 19 & 910 & 0.14 & $60 \pm 7$ \\
\hline $7(15)$ & $\mathrm{D}$ & $2: 42$ & 28 & 1500 & 0.15 & $28 \pm 6$ \\
\hline $8(16)$ & $\mathrm{D}$ & $1: 48$ & 19 & 339 & 0.06 & $38 \pm 7$ \\
\hline $9(18)$ & $\mathrm{D}$ & $2: 12$ & 23 & 556 & 0.07 & $39 \pm 10$ \\
\hline $10(20)$ & $\mathrm{D}$ & $1: 30$ & 16 & 590 & 0.11 & $40 \pm 1$ \\
\hline $11(29)$ & $\mathrm{D}$ & $2: 12$ & 23 & 1061 & 0.13 & $40 \pm 8$ \\
\hline
\end{tabular}

A two-dimensional Fourier transform is applied to the pixel intensity data, $I(x, t)$, at each transect, defined as

$$
\hat{I}\left(k_{x}, f\right)=\iint I(x, t) e^{-i 2 \pi k_{x} x} e^{-i 2 \pi f t} d x d t,
$$

where $\hat{I}\left(k_{x}, f\right)$, is the Fourier transform as a function of frequency $(f)$ and cross-shelf wavenumber $\left(k_{x}\right)$. The two-dimensional spectrum, $S\left(k_{x}, f\right)$, is computed as

$$
S\left(k_{x}, f\right)=\hat{I}\left(k_{x}, f\right) \hat{I}\left(k_{x}, f\right)^{*},
$$

where the asterisk $(*)$ denotes the complex conjugate. By identifying the location of the peak in spectral energy within frequency-wavenumber space $\left(k_{x}, f\right)$, a crossshelf propagation speed was calculated $\left(V=f / k_{x}\right)$. As discussed below, the average internal wave speed in this study was $0.15 \pm 0.10 \mathrm{~m} \mathrm{~s}^{-1}$. Transects from pixel time series whose 2D FFT-derived propagation speed fell in this range were determined to contain an internal wave. The second algorithm, a counterpart to the abovementioned method, used time-space lagged cross correlations where contours of maximum correlation were compared to the average wave speed. This method is discussed in the appendix, and yields similar results though it was not found to be as effective in discerning waves from other features.

The frequency-wavenumber (FFT) and time-space [cross correlation (XCor)] wave-detection algorithms applied to intensity data from the 15 August pixel time series example are presented in Figs. $6 \mathrm{~b}$ and $6 c$. With both methods, the feature's speed falls within the range $0.15 \pm 0.10 \mathrm{~m} \mathrm{~s}^{-1}$ (the average propagation speed of tracked waves), and would be identified as containing an internal wave.

\section{Results}

\section{a. Results from combined in situ and remote sensing experiment}

Background conditions during the experiment were typical of the Oregon summer upwelling season (Fig. 7). Coastal winds measured at the Newport National Data Buoy Center (NDBC) Coastal-Marine Automated Network (C-MAN) station were predominantly from the north, reaching $10 \mathrm{~m} \mathrm{~s}^{-1}$ with a notable period where winds reversed direction (20-25 August). Surface gravity wave forcing was low with offshore significant wave heights rarely reaching above $2 \mathrm{~m}$. The amount of available light and the moisture content of the atmosphere between the camera and the object (ocean surface) both have an impact on the quality of images gathered and the success of optical remote sensing. Though there were no external measurements of these parameters, the Argus images themselves were used to create an image clarity index by comparing contrast levels within the image. Two pixels were chosen, above and below the horizon, representative of an atmospheric and a sea surface measurement, respectively. The clarity index for a clear (unclear) image is assigned a value of $1(0)$ if the contrast between the pixels is above (below) a threshold of 0.9 (Fig. 3). Successive clarity indexes are averaged into hourly intervals, yielding the percent of good images within each viewing hour. Near the beginning of the combined study period (early August), there were predominantly clear days with good viewing conditions (Fig. 7d). Toward the end of the experiment (after 20 August) and coincident with the wind relaxation, there was a large increase in hours where images retrieved were unclear and not useful for this work.

Over the month-long experiment, 11 wave events were tracked as they propagated across the inner shelf (Table 2). With one exception, all tracked waves were 
(a) 2-Hz pixel time series

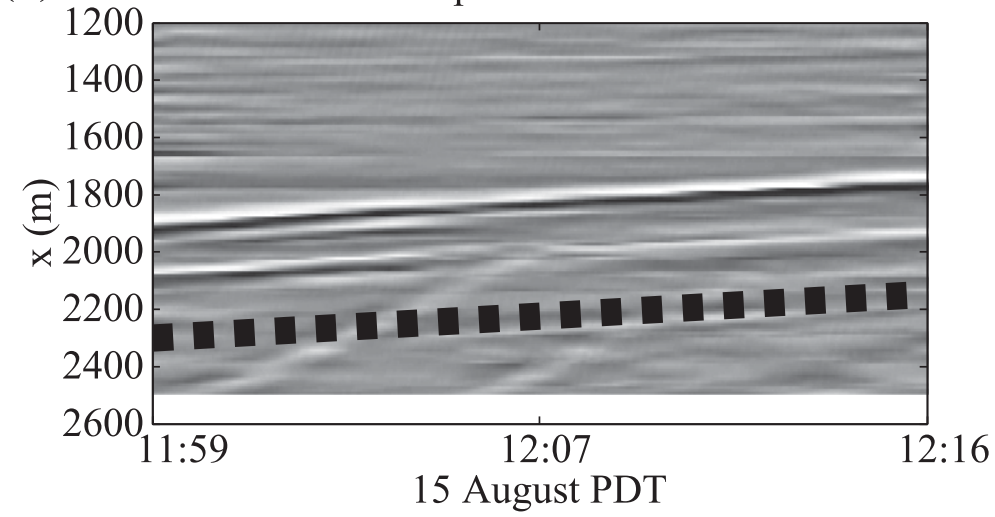

(b)
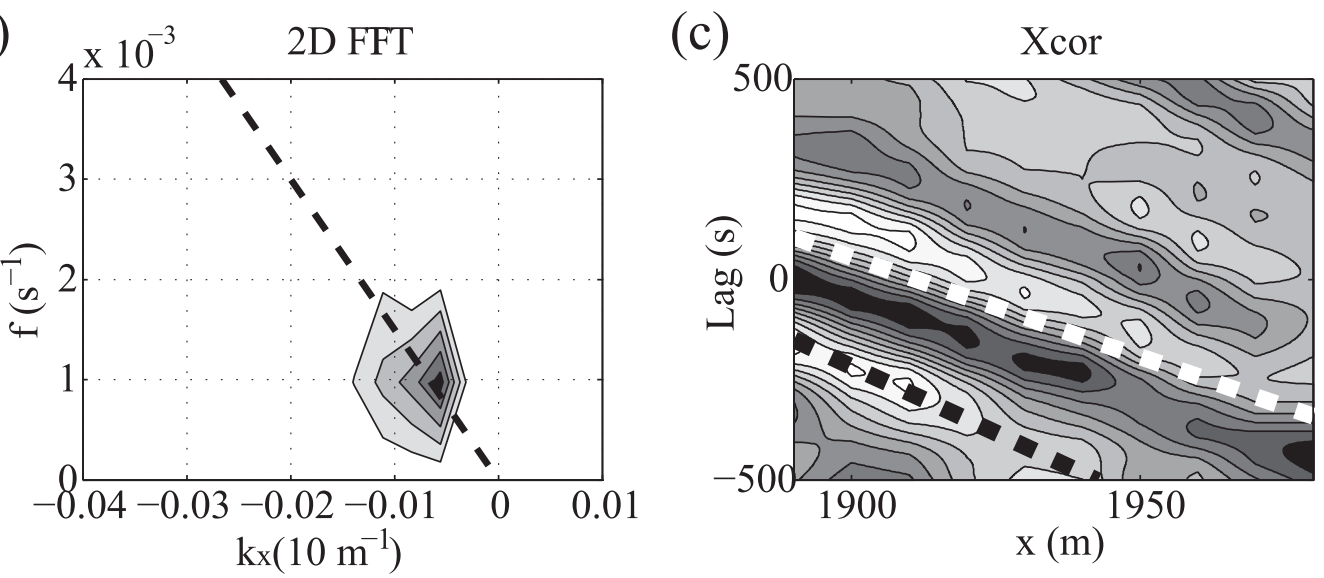

FIG. 6. Intensity transect in pixel time series and examples of wave-detection algorithm. (a) Cross-shelf distance vs time plot of image intensity from $2-\mathrm{Hz}$ pixel time series. Transect has been high-pass filtered to remove spatial variability $>150 \mathrm{~m}$. Period of archival sampling is noted by the vertical white line in Fig. 5. The same front propagates from $x$-shelf distance $\sim(2000-1800)$ in the 17-min sampling period. (b) Two-dimensional spectrum from the Fourier transform of the field shown in (a). (c) Contour plot of lag correlation between pixel time series from $x$-shelf distance 1900 to successive offshore pixels in (a). Dashed white line follows the maximum in lagged correlation. In all plots, the dashed black line corresponds to a feature propagating onshore at $0.15 \mathrm{~m} \mathrm{~s}^{-1}$.

depression waves. The observation of an elevation wave with a visible surface signature is perhaps unusual and more work will be needed to understand the surface visibility of elevation waves. All waves were tracked for a period of $1-4 \mathrm{~h}$, resulting in 20-120 Argus images containing the feature. For each wave, between 10 and 40 frames were analyzed for the internal wave characteristics of propagation speed, direction, and region of increased intensity. The variability in distance and time of wave tracking mainly reflected changes in image clarity due to low-lying clouds or fog that entered the camera field of view or changes in the overlying wind speed. The effect of wind speed magnitude will be discussed in section $3 \mathrm{~b}$.

A comparison of the individual Argus- to mooringderived wave properties for the waves tracked during the combined experiment is shown as a series of scatterplots in Figs. 8a-c. In each panel, a dotted diamond symbol represents waves whose ADCP-based propagation speed is greater than the error estimate-a value significantly different from zero within our confidence estimates. The estimates of propagation speed compare favorably; however, Argus estimates are biased higher than in situ estimates, perhaps due to near-surface processes not adequately captured by an ADCP. There is scatter in the individual estimates of wave direction. We also attempted to derive propagation speed and direction from ADCP velocities following the method described by Mirshak and Kelley (2009) and Chang et al. (2011). Results from these methods (not shown) showed comparable estimates of propagation speed, but an equal amount of scatter in the estimate of wave direction. We expand on this result in the Discussion.

The cross-shelf variations of wave direction and propagation speed are examined by taking the average of all wave characteristics tracked by Argus (Fig. 9). The 
(a)

(b)
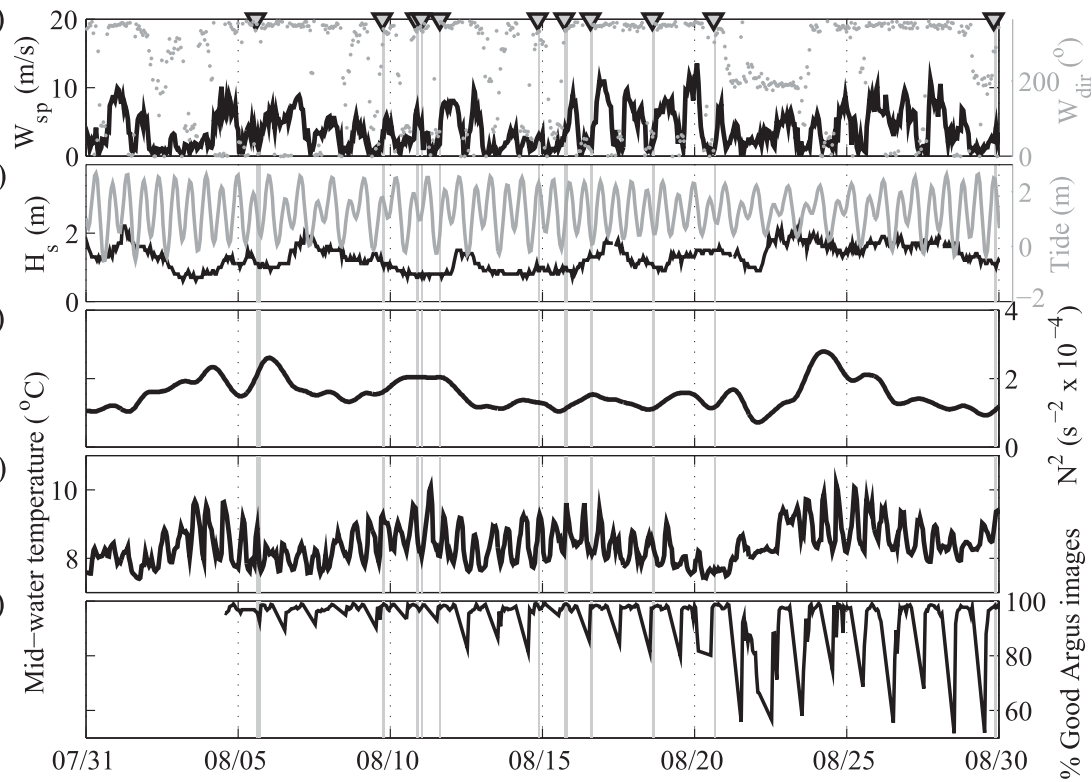

FIG. 7. Background conditions during 2011 experiment. (a) Hourly wind speed and direction from true north gathered by Newport C-MAN station. (b) Significant wave height from NDBC buoy 46050 located $45 \mathrm{~km}$ offshore and tide water level at Newport. (c) Water-column stratification as measured from 20-m mooring. (d) Midwater-column temperature time series from 20-m mooring. (e) Hourly percentage of clear 2-min Argus images. Upside-down gray triangles in (a) and vertical gray lines mark the internal wave features observed in both in situ and Argus images.

average sense of propagation is predominantly onshore. As wave fronts travel across the shelf, the incident angle decreases from $30^{\circ} \pm 5^{\circ}$ at the 20 -m mooring location to $10^{\circ} \pm 5^{\circ}$ at the $10-\mathrm{m}$ mooring, consistent with bathymetric refraction. Mooring-derived direction estimates have large variability. While the average wave direction at $20 \mathrm{~m}$ falls within the range of Argus estimates, the $10-\mathrm{m}$ mooring estimates fall outside this range due to the small number of waves whose properties were estimated at that location. Though the decrease in angle toward shore normal is evident in the Argus-detected waves, no average decrease in propagation speed was observed in either the Argus-detected or in situ measurements. Measured average phase speed from the video imagery was $0.15 \pm 0.10 \mathrm{~m} \mathrm{~s}^{-1}$, larger than the average phase speed of those same waves at the 20-m in situ mooring but comparable to the in situ wave speed measured at $10 \mathrm{~m}$. The accuracy of the georectified images depends on the distance to the camera and the camera orientation. At the farthest distance used here (near the 20-m mooring), the resolution is approximately twice as coarse in the along-shelf direction as opposed to the cross-shelf direction $(45 \mathrm{~m}$ in the along-shelf direction and $20 \mathrm{~m}$ in the cross-shelf direction (see Holman and Stanley 2007).

A theoretical linear phase speed for a mode 1 baroclinic internal wave $\left(c_{\mathrm{ph}}\right)$ can also be found as the eigenvalue to the boundary value problem for the vertical structure of a flat-bottom internal wave given the background stratification profile $\left(N^{2}\right)$

$$
\hat{W}_{\mathrm{zz}}+\frac{N^{2}}{c_{\mathrm{ph}}^{2}} \hat{W}=0
$$

subject to the boundary condition $[\hat{W}=0$, at $z=(0,-D)]$, where $D$ is the water-column depth. Background stratification,

$$
N^{2}=-\frac{g}{\rho_{0}} \frac{\partial \rho(z)}{\partial z}
$$

is a function of the vertical density gradient, itself a function of salinity, temperature, and pressure $[\rho(z)=$ $\rho(S, T, p)]$. As salinity was only measured at the surface and bottom of the water column, a linear relationship between temperature and salinity was assumed to obtain density estimates from discrete temperature-only measurements. The relationship $(S=34.54-0.09 T)$ was determined by linear regression of the concurrent temperature and salinity measurements similar to previous studies from other Oregon inner-shelf locations (Kirincich and Barth 2009). For each of the Argus-tracked waves, all 
(a)

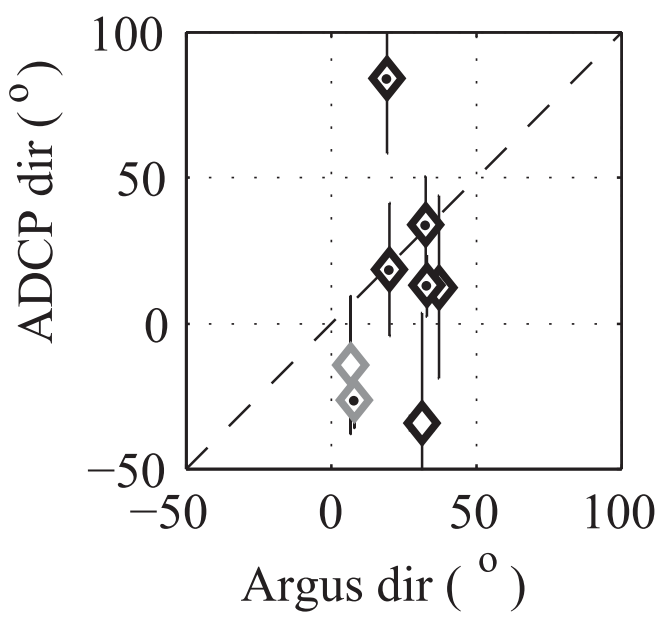

(b)

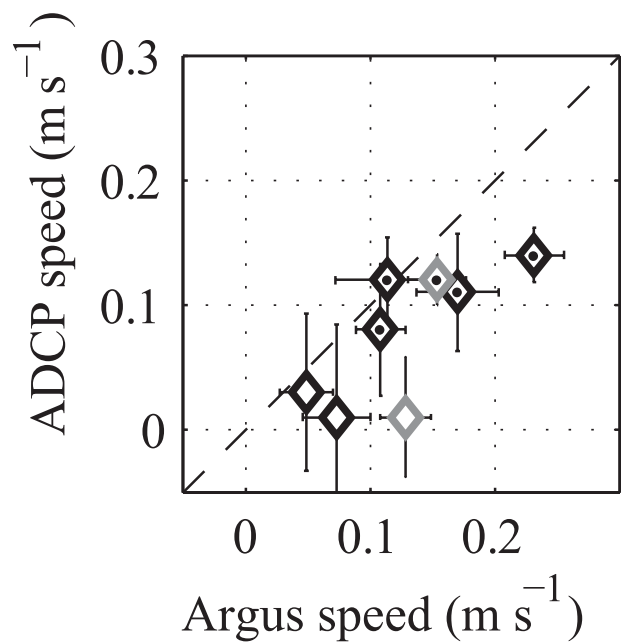

(c)

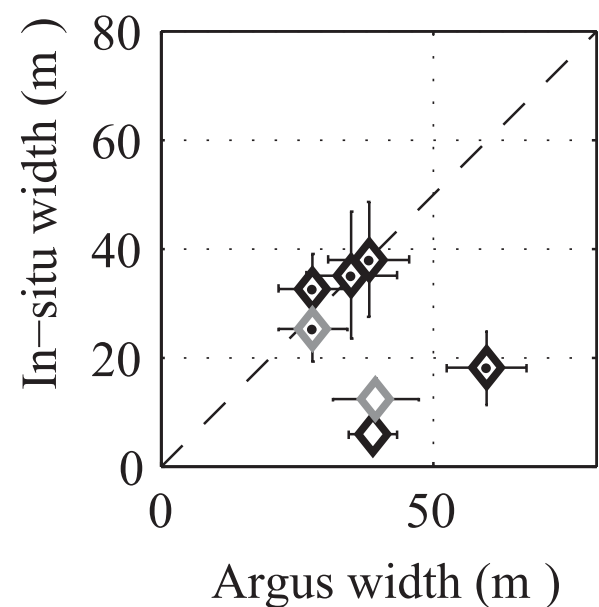

FIG. 8. Comparison of wave properties estimated from Argus and in situ. Black (gray) diamonds are waves that pass directly over the $20-\mathrm{m}(10 \mathrm{~m})$ mooring. Black-dotted diamonds are waves whose ADCP-derived speeds are significantly different from zero. (a),(b) ADCP-derived vs Argus-derived direction and speed, respectively, and (c) ADCP- and density-derived convergence width vs Argusderived width. mooring-recorded temperature measurements from the preceding hour are converted to density. These values are then sorted and interpolated to give a single surfaceto-bottom density profile, which is used to calculate the background stratification and solve for the theoretical wave phase speed. Practically all Argus-measured features propagated faster than these linear phase speeds. This is a frequently observed behavior of shorewardpropagating, nonlinear internal waves in coastal areas because of the amplitude-dependent phase speed correction (e.g., Apel et al. 1985; Stanton and Ostrovsky 1998; Shroyer et al. 2011; Walter et al. 2012). The largest signature of an internal wave is seen from interior measurements of vertical velocity and stratification. The automated algorithm described in section $2 \mathrm{a}(1)$ detected a large number of internal waves from the moorings. In comparing the number of wave events captured by the in situ measurements $(\sim 200)$ with the number of waves observed by remote sensing during the study (11), it is apparent that there are many more internal events than those captured by the video observations. Measurements from video remote sensing are confined to daylight hours that are free of rain and fog, limitations not experienced by the in situ measurements. These limitations are summarized in Table 3 by comparing the number of hours containing internal waves from the mooring record with those from Argus. Excluding the evening hours and unclear conditions, the number of potentially observed waves is 105 . With Argus only $23 \mathrm{~h}$ of wave observations were made ( $22 \%$ success rate). This success rate has yet to account for the variable state of the sea surface, primarily a function of overlying wind speed, which also affects the success of optical measurement. This effect is quantified in the next section by using a longer set of pixel time series video data.

\section{b. Results from pixel time series collections}

During the 5-month period analyzed for internal waves, about 80 wave events were identified through the wave-detection algorithm. Those identified wave events that occurred during the combined experiment are presented along with the results from the tracked waves in the day-hour plot (Fig. 10a). Here, the $x$ axis represents the hour of the day in August plotted on the $y$ axis. Shaded regions give the identified waves from the 2-min sampling, while open circles represent each 17-min pixel time series collection. Results from the FFT and XCor analysis are both presented by an addition of symbols to the open circles. Results are more or less restrictive depending on how many of the nine transects contain a $-0.15 \pm 0.10 \mathrm{~m} \mathrm{~s}^{-1}$ propagating feature (the average propagation speed of the tracked waves). In general, the XCor method was not as restrictive, and it 
(a)

\section{Incident angle}

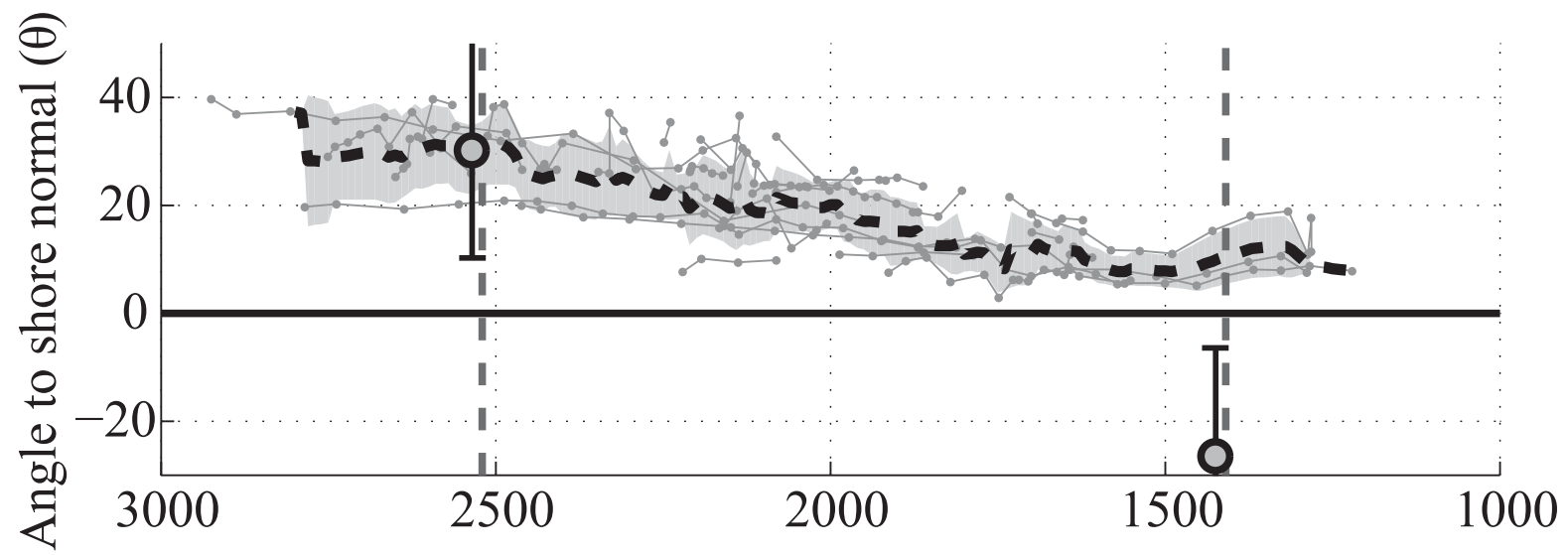

(b)

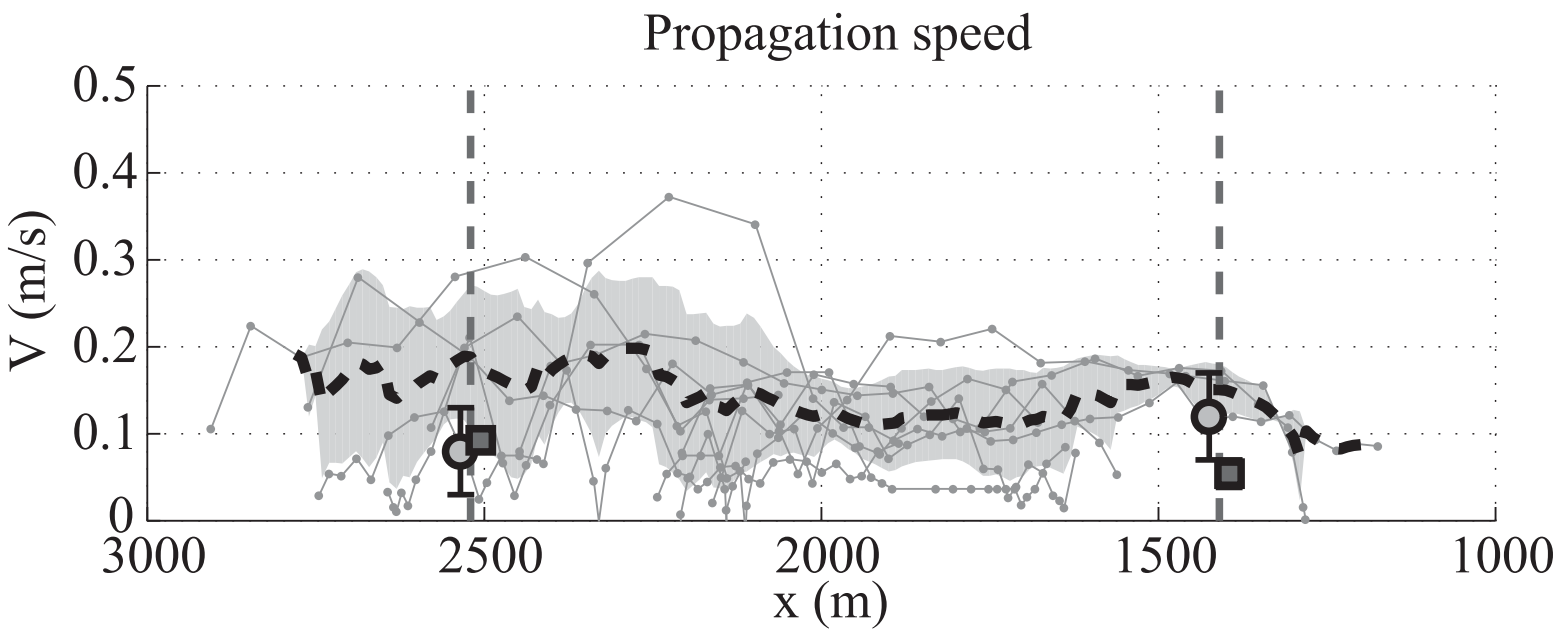

FIG. 9. Summary of observations from Argus-tracked waves with average values from in situ estimates noted in small gray circles. Error bars represent 1 standard deviation from this mean. (a) Angle to shore normal vs distance from shore. Thick line denotes average of all tracked streaks \pm 1 standard deviation in gray. Vertical lines denote mooring positions. (b) Propagation speed vs distance from shore; thick lines as in (a). Dark gray-filled black boxes are the theoretical linear phase speed estimates described in the text.

identified many more internal wave features than the FFT method.

For direct comparison of the pixel time series detections to the tracked waves during the combined experiment, we focus attention on the FFT detections with at least two transects containing an internal wave (periods marked by black-filled symbols in Fig. 10). The first two waves (5-9 August) occurred during a period when the hourly pixel time series collections were not being conducted. Of the remaining nine waves, all but one were successfully detected by the FFT detection. One event (24 August) also resulted in a false positive. This occurred on a day with many hours of unclear images interspersed with periods of clarity (Fig. 5e). Upon returning to the 2-min images for that day, around 1000 PDT the sea surface did exhibit multiple clear streaks near the in situ moorings. Additionally, multiple sharp thermal oscillations were also visible in the in situ data at that time. However, these measurements were not included in the tracked waves because there was no direct mooring crossing visible within the imagery, and it was unclear which streak was associated with the signal seen in the moored data.

Two of the August days are shown in the panels of Fig. $10 \mathrm{~b}$, where in addition to the symbols in Fig. 10a, the sea level record from Newport is also plotted. The internal waves arrived at different phases of the tide on these two days, demonstrating a lack of consistent phase relation between the internal and surface tides. This highlights the difficulty in predicting wave arrival and further emphasizes the need for consistent monitoring of these features (Nash et al. 2012).

Expanding the identification of waves by FFT detection to the full 5-month data record resulted in 1159 pixel time 
TABLE 3. Numbers of hours of internal wave observing from the various platforms during the combined experiment. All percentages are from the total number of hours except were footnoted.

\begin{tabular}{lrc}
\hline \hline & No. & $\begin{array}{c}\text { Percent of } \\
\text { total (\%) }\end{array}$ \\
\hline Hours during combined experiment & 840 & 100 \\
Hours of darkness (2000-0600 PDT) & 315 & 38 \\
Hours of "unclear" viewing conditions & 65 & 8 \\
Hours of Argus viewing & 460 & 55 \\
Hours of Argus observed waves & 23 & $5^{\mathrm{a}}$ \\
Hours with waves present in mooring record & 217 & 26 \\
Hours of waves in dark & 86 & $40^{\mathrm{b}}$ \\
Hours of waves in "unclear" conditions & 26 & $12^{\mathrm{b}}$ \\
Hours of potentially observable waves & 105 & 13 \\
Hours of Argus observed waves & 23 & $22^{\mathrm{c}}$ \\
\hline
\end{tabular}

${ }^{a}$ From hours of Argus viewing (460).

${ }^{\mathrm{b}}$ From total hours of waves in mooring record (217).

${ }^{\mathrm{c}}$ From total hours with potentially observable waves (105).

series collections, 84 of which contained internal waves. Though without an in situ presence, it was impossible to determine with full certainty that the measured feature was indeed an internal wave; this suggests that $7 \%$ of the archived video observations contain an internal wave streak. This is comparable to the percentage of time that internal waves were tracked in the combined experiment $(5 \%)$.

A histogram of wind speeds during which these waves were successfully observed by remote sensing (light bars, right axis, Fig. 11) shows that the majority of the waves are visible during weak to moderate winds (wind speeds between 2 and $5 \mathrm{~m} \mathrm{~s}^{-1}$ ). When compared to the wind speed distribution during hours without waves (dark bars, left axis, Fig. 11), not only is there a difference in the shape of the distribution, with higher wind speeds absent in the former, but the mean wind speed is also shifted toward lower values $\left(3.6 \mathrm{~m} \mathrm{~s}^{-1}\right.$ in collections with waves, and $4.7 \mathrm{~m} \mathrm{~s}^{-1}$ in collections without). This reflects one reason why many waves reported in Table 3 were not observable by video. A light wind does not affect the successful observation of internal wave surface signatures, but strong winds create a noisy sea state that erases the surface variability associated with internal waves. While some wind might be needed for radar observations, we know of no similar minimum for optical measurements. There are other factors that also could influence the wave surface signature. These will likely be associated with variable internal dynamics within individual waves and will be explored in future work.

\section{Discussion}

Estimates of propagation speed and convergence width are comparable for the individual cases captured here; however, there is considerable range in the comparison of Argus- and mooring-derived wave propagation direction (Figs. 8a-c). We attribute the scatter in propagation direction to the large difference in footprint size between the mooring and Argus estimates. In the image data, the convergence region associated with the internal wave is elongated over many kilometers in the along-shelf direction and a $1.5-\mathrm{km}$ region is used to determine the propagation direction. The spread between ADCP beams in $20 \mathrm{~m}$ of water results in a much smaller $200-\mathrm{m}^{2}$ footprint. The discrepancy between the mooring and Argus footprints is even larger in shallower water. There are many processes within an internal wave and in the medium through which it is propagating that can cause variations, especially in propagation direction, on scales shorter than these footprint sizes, such as refraction or along-wave-front instabilities. Furthermore, the borelike internal wave shape found on the inner shelf creates ambiguity in separating wave velocities from the background velocity field, an important distinction before accurately deriving wave propagation speed and direction (e.g., Mirshak and Kelley 2009; Chang et al. 2011).

One example of a future research question that these data evoked is to consider the effect of bottom bathymetry. The waves at Yaquina Head traverse a shallow reef whose effects on the internal wave dynamics in this area are yet to be studied. Future work can also include such processes as wave-wave interaction at this location (e.g., Wang and Pawlowicz 2011). Some of the internal wave surface signatures also remain visible to the edge of the surf zone, where the interaction of these features with surf zone processes can be investigated. In addition to internal wave surface signatures, Pawlowicz (2003) observed the evolution of nearshore turbulent boils with video imagery. Extending these methods to other innershelf processes, such as freshwater intrusions or surface topographic fronts, are also possible uses of video remote sensing.

While combining continuous remote sensing with water-column measurements remains the most effective method for observing these features, it is not presently a feasible solution to the goal of long-term monitoring. One method explored here is to use a subsample of pixels from an image. Though the details of streak evolution are not revealed with the hourly collection of images over $17 \mathrm{~min}$, an algorithm to detect propagating features within these collections compared favorably to the tracked waves with continuous 2-min imagery. Future work can include developing the methods to isolate an internal wave streak and derive propagation speed and direction from the subsampled pixels. Another alternative would be to create an automated, adaptive optical sampling protocol. 
(a)

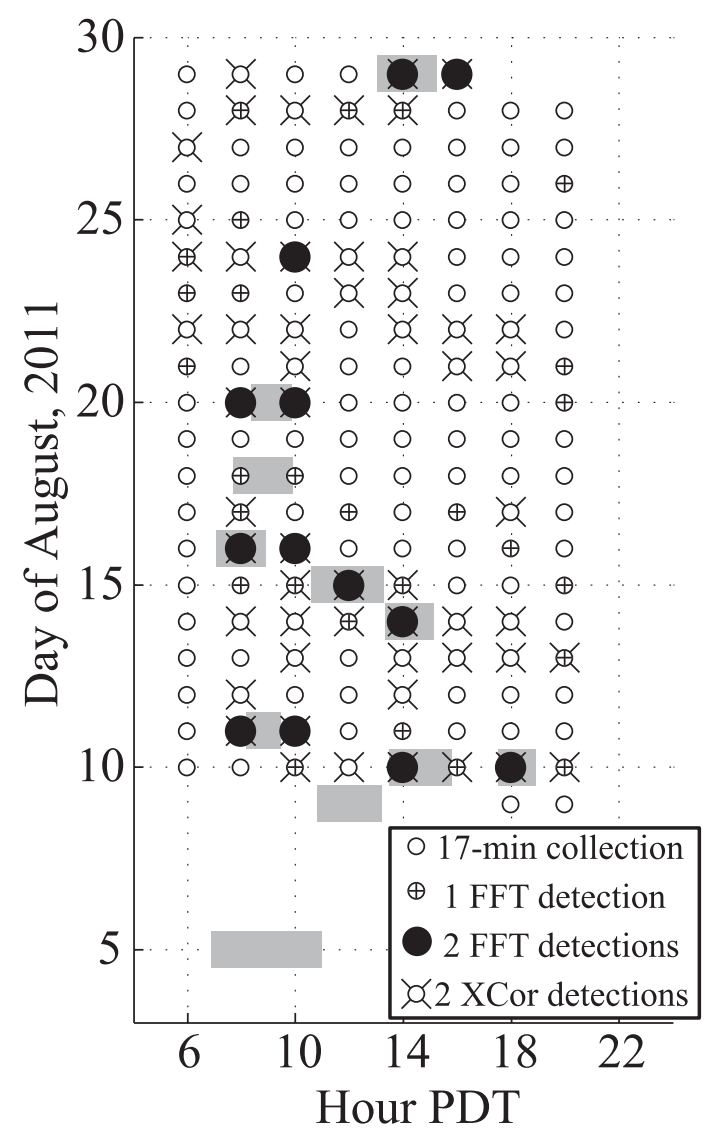

(b)
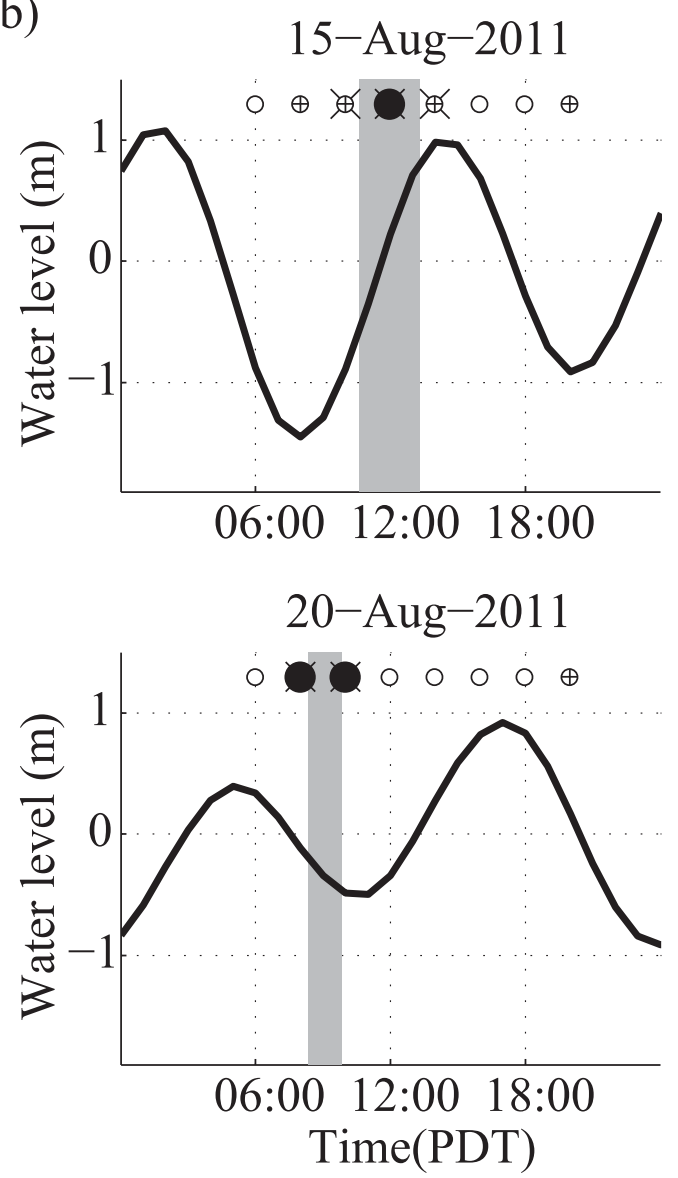

FIG. 10. (a) Day-hour plot of each Argus archived 17-min pixel time series during the combined experiment. Shaded areas mark the 11 identified waves in 2-min data that are compared to in situ measurements and tracked in this paper. Symbols represent wave identification by automated 2D FFT and lagged XCor algorithms. The 1 FFT and 2 FFT notation represent whether one or two transects, respectively, were determined to contain a wave. (b) Two days of daily sea level at Newport: (top),(bottom) 15 and 20 Aug 2011, respectively. Symbols as in (a).

Internal-wave-finding algorithms could be run on temporarily stored image data, and those determined to contain a streak could trigger a more intensive internal wave video sampling strategy to capture the details of propagation.

The research here expands the work of Pawlowicz (2003) toward a methodology for continuous monitoring of internal waves with video observations by demonstrating the feasibility of observing these features using a shore-based permanent installation of video cameras (e.g., Argus). Consistent monitoring is motivated by attempts to identify the source of internal waves and to understand the timing of their arrival to the nearshore. While the use of only video cameras to monitor internal features would be a cost-effective solution, the current impediments to video observations, such as image clarity and wind speed requirements, indicate that more work is needed to demonstrate their utility. Once a robust probability estimate of streak arrival is achieved, such information can be used to plan future field experiments.

\section{Conclusions}

In this work, we have shown how shore-based video remote sensing can be used as a tool for observing and continually monitoring shoreward-propagating internal waves across the inner shelf. When combined with in situ measurements, the 2-min sampling of the sea surface offers several useful measures. Single or widely spaced moorings provide observations in one spatial dimension (depth). Sequential plan-view video images of the sea surface provide the second and third spatial dimensions to clearly show the full 3D spatial structure of these shallow-water internal waves. The evolution of internal wave characteristics, such as propagation speed and direction, are efficiently captured by video remote sensing 


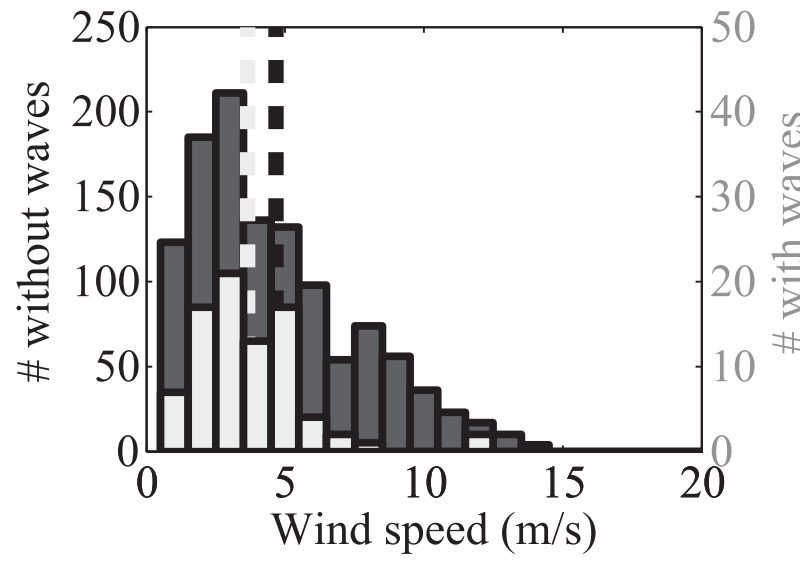

FIG. 11. Histogram of average hourly wind speed during each pixel time series collection over the 5-month period of analysis that contains a wave (light bars, right axis) and those that do not (dark bars, left axis). Distribution averages are marked by vertical dashed lines.

as these features traverse the inner shelf. At this location, internal waves experienced refraction by bathymetry, and measured wave speeds $\left(\sim 0.15 \mathrm{~m} \mathrm{~s}^{-1}\right)$ were higher than predicted by linear theory $\left(<0.1 \mathrm{~m} \mathrm{~s}^{-1}\right)$. While the number of simultaneous observations of waves with in situ and video remote sensing (11) was relatively small during August 2011, future studies at this location should be encouraged by the permanent installation of seawardlooking video cameras as well as the relative proximity of this location to OSU marine operations. Accounting for periods of poor viewing conditions (due to fog, variations in wind speed, and low light), our results show that about $22 \%$ of these potentially observable internal waves have clear surface expressions.

There is a large archive of historical Argus data collection, including those from other Argus stations around the world that could be analyzed for internal wave occurrences. While the Argus program is a well-developed system with invaluable data collection and management protocols, opportunities exist for using other camera platforms, such as beach webcams, to observe these features.

Acknowledgments. Support for this work comes from NSF Grants OCE-0851486 and OCE-1155863. The Argus program is supported by ONR Littoral Geosciences and Optics Grant N00014-09-10121. This work is supported by the Partnership for Interdisciplinary Studies of Coastal Oceans (PISCO), funded by the David and Lucile Packard Foundation and the Gordon and Betty Moore Foundation. The authors acknowledge Jim Lerczak, Ed Dever, and Jonathan Nash for a generous instrument loan. We also thank Kim Page-Albins, the PISCO summer field team, and the captain and crew of R/V Elakha for ship operations in mooring deployment and recovery. Aurelie
Moulin and two anonymous reviewers provided invaluable comments toward improving this manuscript.

\section{APPENDIX}

\section{Time-Domain-Based Internal Wave Identification}

A time-domain-based method to identify internal wave streaks in 17-min Argus collections was also explored. The method was as follows: pixel time series from each 17-min sampling period are interpolated to fall along three cross-shelf transects extending $2 \mathrm{~km}$ from near the coastline to the $20-\mathrm{m}$ isobaths $[x=$ (700:2700), $y=(100,500,900)$ in Argus coordinates]. Each pixel time series in the interpolated transect is lowpass filtered to remove the signature of surface gravity waves (retaining variability with periods greater than $1 \mathrm{~min}$ ). Midway through the data collection (around $7 \mathrm{~min}$ ), the three largest peaks in image intensity from each transect are identified. A time-lagged cross correlation is performed to compare each pixel of maximum intensity with pixels located offshore of the identified feature (see Fig. 6c). The line slope in lag correlation versus cross-shelf distance space gives the speed of cross-shelf propagation. The feature is identified as a potential internal wave if the feature propagates onshore within the range $0.15 \pm 0.10 \mathrm{~m} \mathrm{~s}^{-1}$. Each transect is treated similarly, and if identified features within this range are repeated at similar cross-shelf locations in more than one transect, then the sampling period is taken to contain an internal wave.

\section{REFERENCES}

Apel, J. R., J. R. Holbrook, A. K. Liu, and J. J. Tsai, 1985: The Sulu Sea Internal Soliton Experiment. J. Phys. Oceanogr., 15, 16251651, doi:10.1175/1520-0485(1985)015<1625:TSSISE $>2.0$. CO;2.

Bourgault, D., D. C. Janes, and P. S. Galbraith, 2011: Observations of a large-amplitude internal wave train and its reflection off a steep slope. J. Phys. Oceanogr., 41, 586-600, doi:10.1175/ 2010JPO4464.1.

Chang, M.-H., R.-C. Lien, Y. J. Yang, T. Y. Tang, and J. Wang, 2008: A composite view of surface signatures and interior properties of nonlinear internal waves: Observations and applications. J. Atmos. Oceanic Technol., 25, 1218-1227, doi:10.1175/2007JTECHO574.1.

$\ldots, \ldots, \ldots$, and —_, 2011: Nonlinear internal wave properties estimated with moored ADCP measurements. J. Atmos. Oceanic Technol., 28, 802-815, doi:10.1175/ 2010JTECHO814.1.

Chickadel, C. C., R. A. Holman, and M. H. Freilich, 2003: An optical technique for the measurement of longshore currents. J. Geophys. Res., 108, 3364, doi:10.1029/2003JC001774.

D'Asaro, E. A., R. C. Lien, and F. Henyey, 2007: High-frequency internal waves on the Oregon continental shelf. J. Phys. Oceanogr., 37, 1956-1967, doi:10.1175/JPO3096.1. 
Helfrich, K. R., 1992: Internal solitary wave breaking and run-up on a uniform slope. J. Fluid Mech., 243, 133-154, doi:10.1017/ S0022112092002660.

Henyey, F. S., and A. Hoering, 1997: Energetics of borelike internal waves. J. Geophys. Res., 102, 3323-3330, doi:10.1029/ 96JC03558.

Holman, R. A., and J. Stanley, 2007: The history and technical capabilities of Argus. Coastal Eng., 54, 477-491, doi:10.1016/ j.coastaleng.2007.01.003.

Jackson, C. R., 2004: An Atlas of Internal Solitary-Like Waves and Their Properties. 2nd ed. Global Ocean Associates, 560 pp. [Available online at http://www.internalwaveatlas.com.]

Kirincich, A. R., and J. A. Barth, 2009: Time-varying across-shelf Ekman transport and vertical eddy viscosity on the inner shelf. J. Phys. Oceanogr., 39, 602-620, doi:10.1175/2008JPO3969.1.

Kropfli, R. A., L. A. Ostrovski, T. P. Stanton, E. A. Skirta, A. N. Keane, and V. Irisov, 1999: Relationships between strong internal waves in the coastal zone and their radar and radiometric signatures. J. Geophys. Res., 104, 3133-3148, doi:10.1029/ 98JC02549.

Leichter, J. J., S. R. Wing, S. L. Miller, and M. W. Denny, 1996: Pulsed delivery of subthermocline water to Conch Reef (Florida Keys) by internal tidal bores. Limnol. Oceanogr., 41, 1490-1501, doi:10.4319/lo.1996.41.7.1490.

Mirshak, R., and D. E. Kelley, 2009: Inferring propagation direction of nonlinear internal waves in a vertically sheared background flow. J. Atmos. Oceanic Technol., 26, 615-625, doi:10.1175/2008JTECHO632.1.

Moum, J. N., J. M. Klymak, J. D. Nash, A. Perlin, and W. D. Smyth, 2007: Energy transport by nonlinear internal waves. J. Phys. Oceanogr., 37, 1968-1988, doi:10.1175/JPO3094.1.

Nash, J. D., S. M. Kelly, E. L. Shroyer, J. N. Moum, and T. F. Duda, 2012: The unpredictable nature of internal tides on continental shelves. J. Phys. Oceanogr., 42, 1981-2000, doi:10.1175/ JPO-D-12-028.1.

Pawlowicz, R., 2003: Quantitative visualization of geophysical flows using low-cost oblique digital time-lapse imaging. IEEE J. Oceanic Eng., 28, 699-710, doi:10.1109/JOE.2003.819310.
Pineda, J., 1999: Circulation and larval distribution in internal tidal bore warm fronts. Limnol. Oceanogr., 44, 1400-1414, doi:10.4319/ lo.1999.44.6.1400.

Ramos, R. J., B. Lund, and H. C. Graber, 2009: Determination of internal wave properties from X-band radar observations. Ocean Eng., 36, 1039-1047, doi:10.1016/ j.oceaneng.2009.07.004.

Scotti, A., and J. Pineda, 2004: Observation of very large and steep internal waves of elevation near the Massachusetts coast. Geophys. Res. Lett., 31, L22307, doi:10.1029/2004GL021052..

_ B. Butman, R. C. Beardsley, P. S. Alexander, and S. Anderson, 2005: A modified beam-to-earth transformation to measure short-wavelength internal waves with an acoustic Doppler current profiler. J. Atmos. Oceanic Technol., 22, 583-591, doi:10.1175/JTECH1731.1.

Shroyer, E. L., J. N. Moum, and J. D. Nash, 2011: Nonlinear internal waves over New Jersey's continental shelf. J. Geophys. Res., 116, C03022, doi:10.1029/2010JC006332.

Stanton, T. P., and Ostrovsky, L. A., 1998: Observations of highly nonlinear internal solitons over the continental shelf. Geophys. Res. Lett., 25, 2695-2698, doi:10.1029/98GL01772.

Venayagamoorthy, S. K., and O. B. Fringer, 2007: On the formation and propagation of nonlinear internal boluses across a shelf break. J. Fluid Mech., 577, 137-159, doi:10.1017/ S0022112007004624.

Walter, R. K., C. B. Woodson, R. S. Arthur, O. B. Fringer, and S. G. Monismith, 2012: Nearshore internal bores and turbulent mixing in southern Monterey Bay. J. Geophys. Res., 117, C07017, doi:10.1029/2012JC008115.

Wang, C., and R. Pawlowicz, 2011: Propagation speeds of strongly nonlinear near-surface internal waves in the Strait of Georgia. J. Geophys. Res., 116, C10021, doi:10.1029/2010JC006776.

Wong, S. H. C., A. E. Santoro, N. J. Nidzieko, J. L. Hench, and A. B. Boehm, 2012: Coupled physical, chemical, and microbiological measurements suggest a connection between internal waves and surf zone water quality in the Southern California Bight. Cont. Shelf Res., 34, 64-78, doi:10.1016/ j.csr.2011.12.005. 